\title{
PENETAPAN KADAR FLAVONOID TOTAL EKSTRAK DAUN CENGKEH (Syzygium aromaticum (L.) Merr \& Perry)
}

\author{
Wahyulianingsih ${ }^{1}$, Selpida Handayani, Abd. Malik \\ Fakultas Farmasi, Universitas Muslim Indonesia \\ 1yulialone5@gmail.com
}

\begin{abstract}
Clove (Syzygium aromaticum (L.) Merr \& Perry) is one of the plants used as medicine, society used leaves as anti-inflammatory drugs at the time of toothache, which at the leaf contained flavonoids. The aim of this study is to determine the content of total flavonoid of ethanol extract clove leaf (EECL). Clove leaf was extracted using maceration method with ethanol as a solvent during at $3 \times 24$ hours. Analysis qualitative of flavonoids compound using thin layer chromatography method. Determination of total flavonoids content of clove leaves using spectrophotometri $U V$-Vis method $\lambda 418 \mathrm{~nm}$. The result of the research with rendamen yield of EECL were 16,1134\%, and total flavonoids content is 73,08 $\mathrm{mgRE} / \mathrm{g}$ extract with persentation $7,308 \%$.
\end{abstract}

Keywords: Clove leaf (Syzygium aromaticum (L.) Merr \& Perry), Flavonoids

\section{PENDahuluan}

Indonesia merupakan salah satu Negara yang terkenal akan kekayaan alamnya, yang mana memiliki berbagai jenis tumbuhan yang dapat berkhasiat sebagai obat. Oleh karena itu dilakukanlah berbagai macam penelitian dan pengujian agar khasiat tumbuhan sebagai obat tersebut dapat bersifat lebih rasional dan dipercaya di kalangan masyarakat.

Salah satu tanaman yang dapat berkhasiat sebagai obat adalah daun cengkeh (Syzygium aromaticum (L.) Merr \& Perry). Cengkeh merupakan tanaman rempah yang sejak lama digunakan dalam industri rokok kretek, makanan, minuman dan obat-obatan. Bagian tanaman yang dapat dimanfaatkan untuk keperluan di atas adalah bunga, tangkai bunga dan daun cengkeh. Penggunaan cengkeh untuk keperluan lain diantaranya sebagai bahan anestesi untuk ikan dan pemberantasan hama dan penyakit tanaman. Cengkeh mempunyai komponen eugenol dalam jumlah besar (70-80\%) yang mempunyai sifat sebagai stimulan, anestetik lokal, karminatif, antiemetik, antiseptik dan antispasmodik (Nurdjannah, 2004). Pemisahan kandungan kimia dari serbuk bunga, tangkai bunga dan daun cengkeh menunjukan bahwa serbuk bunga dan daun cengkeh mengandung saponin, tannin, alkaloid, glikosida dan flavonoid, sedangkan tangkai bunga cengkeh mengandung saponin, tannin, glikosida dan flavonoid (Ferdinanti, 2001).

Senyawa flavonoid adalah suatu kelompok senyawa fenol yang terbesar yang ditemukan dialam. Senyawa- senyawa ini merupakan zat warna merah, ungu dan biru dan sebagai zat warna kuning yang ditemukan dalam tumbuh-tumbuhan (Markham, 1988). Golongan flavonoid memiliki kerangka karbon yang terdiri atas dua cincin benzene tersubstitusi yang disambungkan oleh rantai alifatik tiga karbon.
Pengelompokan flavonoid berdasarkan pada cincin heterosiklik- oksigen tambahan dan gugus hidroksil yang tersebar (Robinson, 1995). Golongan terbesar flavonoid memiliki cincin piran yang yang menghubungkan rantai tiga - karbon dengan salah satu cincin benzene (Harborne, 1987).

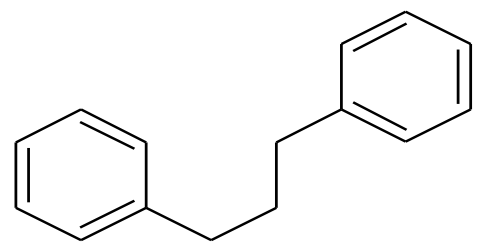

Gambar 1. Struktur Flavonoid (Markham, 1988)

Senyawa flavonoid diturunkan dari unit $\mathrm{C}_{6}{ }^{-}$ $\mathrm{C}_{3}$ (fenilpropana) yang bersumber dari asam sikimat dan unit $\mathrm{C}_{6}$ yang diturunkan dari jalur poliketida. Fragmen poliketida ini disusun dari tiga molekul malonil-KoA, yang bergabung dengan unit $\mathrm{C}_{6}-\mathrm{C}_{3}$ (sebagai koA tioester) untuk membentuk unit awal triketida. Oleh karena itu, flavonoid yang berasal dari biosintesis gabungan terdiri atas unit-unit yang diturunkan dari asam sikimat dan jalur poliketida (Heinrich, et al., 2010).

Flavonoid terdapat pada semua bagian tumbuhan termasuk daun, akar, kayu, kulit, bunga, buah dan biji. Flavonoid terdiri dari beberapa golongan utama antara lain antosianin, flavanol dan flavon yang tersebar luas dalam tumbuhan. Sedangkan khalkon, auron, flavonol, dihidrokhalkon, dan isoflavon penyebarannya hanya terbatas pada golongan tertentu saja (Harborne, 1987).

Sejumlah tanaman obat yang mengandung flavonoid telah dilaporkan memiliki aktivitas antioksidan, antibakteri, antivirus, antiradang, 
antialergi, dan antikanker (Miller, 1996). Senyawa flavonoid diduga sangat bermanfaat dalam makanan karena, berupa senyawa fenolik, senyawa ini yang bersifat antioksidan kuat. Banyak kondisi penyakit yang diketahui bertambah parah oleh adanya radikal bebas seperti superoksida dan hidroksil, dan flavonoid memiliki kemampuan untuk menghilangkan dan secara efektif 'menyapu' spesies pengoksidasi yang merusak ini. Oleh karena itu, makanan yang kaya flavonoid dianggap penting untuk mengobati penyakit-penyakit, seperti kanker dan penyakit jantung (Heinrich, et al., 2010).

\section{METODE PENELITIAN}

\section{A. Pengambilan dan Pengolahan Sampel}

Sampel daun cengkeh (Syzygium aromaticum (L.) Merr \& Perry) di ambil di Moya Kecamatan kota Ternate Tengah. Waktu pengumpulan sampel daun dilakukan saat proses fotosintesis maksimal, yaitu saat mulai berbunga atau sedang berbunga tetapi belum berbuah. Pada saat ini proses fotosintesis berhenti sementara.

Teknik pengumpulan sampel daun dilakukan dengan cara dipetik, maka keterampilan pemetik sangat penting diperhatikan. Keterampilan diperlukan untuk memperoleh simplisia yang benar dan tepat (misalnya kalau diperlukan daun muda, tidak terpetik daun tua dan ranting) serta tidak merusak tanaman induk. Sampel kemudian dibersihkan dari kotoran yang melekat lalu dikeringkan dengan cara dianginanginkan dan disimpan di lemari pengering. Setelah kering, daun cengkeh diblender sampai menjadi serbuk, disimpan ke dalam wadah dan siap untuk diekstraksi.

\section{B. Ekstraksi Sampel}

Ditimbang 500 gram daun cengkeh (Syzygium aromaticum (L.) Merr \& Perry), kemudian dimasukan serbuk simplisia kedalam bejana maserasi. Dituang secara perlahan pelarut etanol $96 \%$ sebanyak 2 L kedalam bejana maserasi yang berisi serbuk simplisia. Setelah itu dibiarkan cairan penyari merendam seluruh serbuk simplisia selama 3 hari sambil diaduk secara periodik. Campiran kemudian disaring dan ampasnya direndam lagi dengan cairan penyari yang baru. Proses penyarian selanjutnya dilakukan sebanyak 2 kali dengan etanol 96\% setiap kali sebanyak 1 L. Ekstrak cair dikumpulkan kemudian dipekatkan dengan menggunakan alat rotavapor (rotary evaporator vacuum) hingga diperoleh ekstrak kental etanol.

\section{Analisis Kualitatif}

Ekstrak yang diperoleh dianalisis kandungan kimianya menggunakan metode kromatografi lapis tipis (KLT). EEDC dilarutkan dengan etanol $96 \%$, kemudian ditotolkan pada fase diam silika gel GF254 dan dielusi dengan fase gerak n-heksan : etil asetat (3:7). Deteksi dilakukan dibawah lampu UV 254 dan $366 \mathrm{~nm}$, dan dengan bantuan pereaksi semprot yang sesuai untuk deteksi senyawa flavonoid yaitu sitro borat, warna atau fluoresensi yang terbentuk adalah fluoresensi kuningkuning kehijauan dibawah sinar UV $366 \mathrm{~nm}$ (Pramono, 1989). Dan $\mathrm{AlCl} 3$ yang berfluoresensi kuning kehijauan (Harbone, 1987). Kemudian dilanjutkan pemanasan $100^{\circ} \mathrm{C}$ selama 1-5 menit, setelah itu diamati dibawah sinar UV $366 \mathrm{~nm}$ berfluoresensi kuning-kuning kehijauan. Kemudian ditentukan nilai Rf-nya untuk setiap noda yang tampak.

\section{Analisis Kuantitatif}

\section{Pembuatan larutan standar rutin}

Ditimbang $10 \mathrm{mg}$ rutin dilarutkan dalam 10 $\mathrm{ml}$ metanol p.a, sehingga menghasilkan konsentrasi $1000 \mathrm{ppm}$. Selanjutnya, larutan rutin diencerkan untuk memberikan serangkaian konsentrasi 37,5 $\mu \mathrm{g} / \mathrm{ml}, 62,5 \mu \mathrm{g} / \mathrm{ml}, 75 \mu \mathrm{g} / \mathrm{ml}, 87,5 \mu \mathrm{g} / \mathrm{ml}$, dan 100 $\mu \mathrm{g} / \mathrm{ml}$. Kemudian dari masing-masing konsentrasi dipipet $0,5 \mathrm{ml}$ dan ditambahkan dengan $1,5 \mathrm{ml}$ methanol, 0,1 ml AlCl3 10\%, 0,1 ml kalium asetat $1 \mathrm{M}$ dan dicukupkan dengan air steril hingga volume 5 ml, kemudian divortex dan diinkubasi selama 30 menit. Sebelum pengukuran, maka dilakukan optimasi panjang gelombang maksimum dari standar rutin. Setelah itu diukur absorbansinya dengan menggunakan spektrofotometri UV-Vis pada panjang gelombang $418 \mathrm{~nm}$.

\section{Pembuatan larutan ekstrak etanol daun cengkeh (EEDC)}

Ditimbang sebanyak 10 mg EEDC dilarutkan dalam $10 \mathrm{ml}$ metanol pa. Dibuat 3 replikasi dengan dipipet masing-masing $0,5 \mathrm{ml}$, kemudian ditambahkan dengan 1,5 ml metanol, 0,1 ml AlCl3 $10 \%, 0,1 \mathrm{ml}$ kalium asetat $1 \mathrm{M}$ dan dicukupkan dengan air steril hingga volume $5 \mathrm{ml}$, kemudian divortex dan diinkubasi selama 30 menit. Setelah itu diukur absorbansinya pada panjang gelombang 418 nm.

\section{E. Analisis Data}

Analisis data dengan persamaan regresi linear menggunakan program Microsoft excel kemudian dihitung kadar flavanoid totalnya. 
III. HASIL DAN PEMBAHASAN

Tabel 1. Hasil perhitungan persen rendamen EEDC (Syzygium aromaticum (L.) Merr \& Perry)

\begin{tabular}{ccccc}
\hline .No & Sampel & $\begin{array}{c}\text { Berat } \\
\text { Awal } \\
(\mathbf{g})\end{array}$ & $\begin{array}{c}\text { Hasil } \\
\text { Ekstrak } \\
(\mathbf{g})\end{array}$ & $\begin{array}{c}\text { Rendamen } \\
\text { Ekstrak } \\
(\boldsymbol{\%})\end{array}$ \\
\hline 1. & EEDC & 500 & 80,5671 & 16,1134 \\
\hline
\end{tabular}

Tanaman cengkeh (Syzygium aromaticum (L.) Merr \& Perry) yang digunakan dalam penelitian ini yaitu hanya pada bagian daunnya. Daun cengkeh yang diambil, terlebih dahulu dicuci untuk menghilangkan kotoran seperti debu ataupun serangga yang menempel yang nantinya dapat mengganggu proses dan hasil ekstraksi. Setelah itu dianginanginkan, kemudian dilakukan pengubahan bentuk pada sampel daun cengkeh untuk memperluas permukaan daun sehingga dapat mempercepat proses pengeringan. Pengeringan ini dimaksudkan untuk mengurangi kadar air, sehingga dapat mencegah pembusukan oleh jamur atau bakteri serta reaksi enzimatik tidak berlangsung.

Dalam penelitian ini, sampel daun cengkeh yang telah dihaluskan ditimbang sebanyak $500 \mathrm{~g}$ dan diekstraksi dengan metode maserasi. Digunakan metode maserasi ini karena daun memiliki tekstur yang lunak dan juga dalam proses ekstraksinya tidak digunakan adanya pemanasan, dimana pemanasan ini dapat membuat kadar dari flavonoid berkurang, sehingga digunakan metode maserasi. Maserasi merupakan cara penyarian sederhana. Dirjen POM (1986) mengatakan, cairan penyari akan menembus dinding sel tanaman dan masuk ke rongga sel yang mengandung zat aktif, sehingga zat aktif akan larut dan karena adanya perbedaan konsentrasi antara larutan zat aktif di dalam sel dengan yang di luar sel, maka larutan yang terpekat akan didesak keluar.

Sampel yang telah ditimbang tadi kemudian dimasukkan ke dalam wadah maserasi dan dimasukkan cairan penyari etanol $96 \%$ sebanyak 2000 mL. Digunakan etanol karena (1) lebih selektif, (2) kapang sulit tumbuh dalam etanol $20 \%$ keatas, (3) tidak beracun, (4) netral, (5) absorbsinya baik, (6) etanol dapat bercampur dengan air dalam segala perbandingan, (7) memerlukan panas yang lebih sedikit untuk proses pemekatan, dan (8) zat penganggu yang larut terbatas (Tenriugi, et al., 2011). Pelarut etanol dipilih sebagai cairan penyari karena senyawa yang akan diekstraksi adalah senyawa fenolik. Ekstraksi senyawa fenolik dari jaringan tumbuhan dalam bentuk glikosida menggunakan pelarut methanol atau etanol pada suhu kamar dengan cara maserasi (Andersen, 2006; Markham, 1988). Hasil maserasi yang diperoleh kemudian disaring untuk memisahkan residu (ampas) dan filtratnya. Residu yang diperoleh kemudian di ekstraksi kembali dengan menambahkan pelarut etanol $96 \% 1000 \mathrm{~mL}$. Penambahan pelarut etanol dilakukan sampai 3 kali proses ektraksi, sehingga volume pelarut yang digunakan yaitu $4000 \mathrm{~mL}$ filtrat yang diperoleh kemudian diuapkan dengan menggunakan rotavapor dibawah titik didih pelarut sehingga didapatkan ekstrak kental. Ekstrak kental yang didapat berwarna hijau tua, dengan persen rendamen yaitu $16,1134 \%$.

Tabel 2. Hasil running panjang gelombang maksimum DPPH 35 ppm

\begin{tabular}{|c|c|c|c|}
\hline \multirow[b]{2}{*}{$\begin{array}{c}\text { Skrininf } \\
\text { Fitokimia }\end{array}$} & \multicolumn{2}{|c|}{ Penyemprotan Pereaksi } & \multirow[b]{2}{*}{ Hasil } \\
\hline & $\begin{array}{c}\mathrm{AlCl}_{3} \\
\text { (Fluoresensi } \\
\left.\mathrm{UV}_{366}\right)\end{array}$ & $\begin{array}{c}\text { Sitroborat } \\
\text { (Fluoresensi } \\
\left.\text { UV }_{366}\right)\end{array}$ & \\
\hline Flavonoid & $\begin{array}{c}\text { Kuning } \\
\text { Kehijauan }\end{array}$ & $\begin{array}{l}\text { Kuning } \\
\text { kehijauan }\end{array}$ & + \\
\hline
\end{tabular}

Keterangan: $+=$ Positif

Pemeriksaan flavonoid secara kualitatif dengan menggunakan metode kromatografi lapis tipis (KLT). Dimana KLT itu sendiri merupakan suatu metode pemisahan suatu senyawa berdasarkan perbedaan distribusi dua fase yaitu fase diam dan fase gerak. Fase diam yang digunakan adalah silika gel GF254, dan fase geraknya n-heksan : etil (3:7). Ketika diamati dibawah UV $366 \mathrm{~nm}$ terlihat noda sedikit berfluoresensi atau berpendar, dan setelah disemprot dengan $\mathrm{AlCl}_{3}$ dan sitroborat dan dipanaskan kemudian diamati dibawah UV $366 \mathrm{~nm}$, noda yang berfluoresensi kuning kehijauan semakin intensif sehingga menunjukan adanya flavonoid.

Penentuan kadar flavonoid total EEDC dengan menggunakan metode kolorimetri alumunium klorida (Chang, et al., 2002). Mujahid (2011) telah melakukan validasi pada metode ini, dimana ia menyatakan bahwa metode ini adalah metode yang terpilih untuk analisis flavonoid secara spektroskopi UV-Vis yang dihitung sebagai rutin, karena menghasilkan parameter yang baik. Flavonoid juga memiliki system karbonil yang terkonjugasi dengan cincin aromatic sehingga karakterisasi flavonoid dapat dilakukan dengan spektrofotometri (Wildah, 2001). Oleh karena itu spektrofotometri UV-Vis digunakan untuk menentukan kadar flavonoid pada EEDC, dimana larutan standar yang digunakan yaitu rutin. Digunakan rutin karena kebanyakan flavonoid paling sering ditemukan dalam bentuk glikosida seperti kuarsetin 3-rutinosida (Harbone, 1987). Larutan standar rutin ini kemudian ditimbang sebanyak $10 \mathrm{mg}$ dan dilarutkan dalam $10 \mathrm{ml}$ metanol kemudian dibuat beberapa rangkaian konsentrasi yaitu $37,5 \mu \mathrm{g} / \mathrm{ml}$, $62,5 \mu \mathrm{g} / \mathrm{ml}, 75 \mu \mathrm{g} / \mathrm{ml}, 87,5 \mu \mathrm{g} / \mathrm{ml}$, dan $100 \mu \mathrm{g} / \mathrm{ml}$. Rangkaian konsentrasi ini dimaksudkan untuk mengurangi ketidakpastian analisa sehingga ketelitian 
akan meningkat (Wiryawan, 2008). Dari beberapa rangkaian konsentrasi tersebut, kemudian dipipet masing-masing $0,5 \mathrm{ml}$ dan ditambahkan dengan 1,5 $\mathrm{ml}$ metanol yang berfungsi sebagai peningkat kelarutan, kemudian ditambahkan $0,1 \mathrm{ml} \mathrm{AlCl} 310 \%$ yang berfungsi untuk memberikan efek batokromik dengan melakukan pergeseran kearah panjang gelombang yang lebih panjang, sehingga mengubah panjang gelombang standar rutin untuk masuk ke dalam range panjang gelombang UV-Vis. Terjadi juga efek hiperkromik atau peningkatan intensitas larutan standar rutin menghasilkan warna yang lebih kuning (Chang et, al., 2002). Setelah itu ditambahkan 0,1 ml $\mathrm{CH} 3 \mathrm{COOK} 1 \mathrm{M}$ yang berfungsi sebagai penstabil. Kemudian dicukupkan dengan air steril hingga volume mencapai $5 \mathrm{ml}$. setelah itu dihomogenkan dengan menggunakan vortex dan diinkubasi selama 30 menit. Hal tersebut dimaksudkan agar reaksi antara larutan standar rutin dengan perekasi-pereaksi yang ditambahkan dapat berlangsung dengan sempurna. Untuk sampel EEDC, ditimbang $10 \mathrm{mg}$ dan dilarutkan dalam $10 \mathrm{ml}$ metanol. Dibuat 3 replikasi dengan masing-masing dipipet $0,5 \mathrm{ml}$ dan ditambahkan dengan 1,5 ml metanol, 0,1 ml $\mathrm{AlCl}_{3} 10 \%, 0,1 \mathrm{ml}$ $\mathrm{CH} 3 \mathrm{COOK} 1 \mathrm{M}$ dan dicukupkan dengan air steril hingga volume $5 \mathrm{ml}$, kemudian di vorteks dan diinkubasi selama 30 menit.

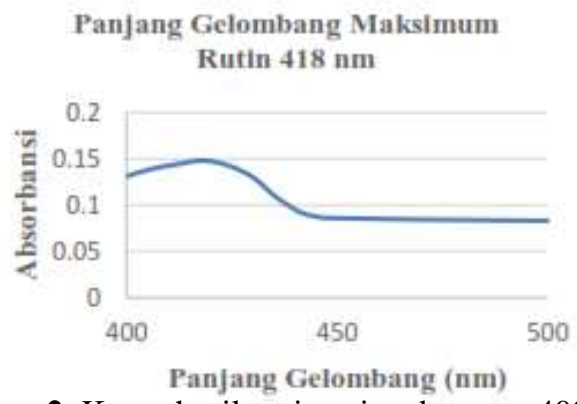

Gambar 2. Kurva hasil optimasi pada range 400-500 $\mathrm{nm}$

Pergeseran ini disebabkan oleh $\mathrm{AlCl}_{3}$ yang membentuk kompleks stabil tahan asam dengan gugus $\mathrm{OH}$ pada atom $\mathrm{C}-5$ atau C-3 dan gugus keton pada atom C-4 (Chang et, al., 2002). Setelah itu dilanjutkan pengukuran absorbansi sampel dan kurva baku pada panjang gelombang $418 \mathrm{~nm}$.

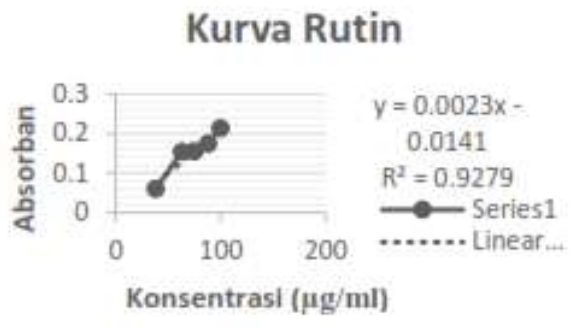

Gambar 3. Kurva linear konsentrasi rutin vs absorban pada $\lambda 418 \mathrm{~nm}$

Hasil kurva kalibrasi linear rutin yang diperoleh yaitu $\mathrm{y}=0,0023 \mathrm{x}-0,0141$ dengan nilai koefisien determinasi $\left(\mathrm{R}^{2}\right)$ yang diperoleh sebesar 0,9279 .

Tabel 3. Hasil penetapan kadar flavonoid total pada EEDC (Syzygium aromaticum (L.) Merr \& Perry)

\begin{tabular}{|c|c|c|c|c|c|}
\hline Sampel & Reollkasi & Absorbansi & $\begin{array}{c}\text { Kandungan } \\
\text { Flavonoid } \\
\text { Awal } \\
\text { (mgiml) }\end{array}$ & $\begin{array}{l}\text { Kandungan } \\
\text { Flavonoid } \\
\text { Total (moRE } \\
\text { I g ekstrak) }\end{array}$ & $\begin{array}{c}\text { \% Kadar } \\
\text { flavonoid } \\
\text { total }\end{array}$ \\
\hline & 1 & 0.144 & 0,03873 & 68,73 & 6,873 \\
\hline \multirow[t]{3}{*}{ EEDC } & 2 & 0.122 & 0,05817 & 50,17 & 5917 \\
\hline & 3 & 0,196 & 0,09134 & 91,34 & 9,135 \\
\hline & \multicolumn{3}{|c|}{ Rata-rata } & 7398 & 7,338 \\
\hline
\end{tabular}

Dari pengujian kuantitatif ini, diperoleh kadar flavonoid total ekstraketanol daun cengkeh (Syzygium aromaticum (L.) Merr \& Perry) sebesar 73,08 $\mathrm{mgRE} / \mathrm{g}$ ekstrak dengan persentase 7,308\% yang dihitung sebagai rutin ekuivalen.

\section{KESIMPULAN}

Berdasarkan hasil penelitian yang dilakukan dapat disimpulakan bahwa: Berdasarkan hasil penelitian, disimpulkan bahwa ekstrak etanol daun cengkeh (Syzygium aromaticum (L.) Merr \& Perry) memiliki kadar flavonoid total sebesar 73,08 mgRE/g ekstrak dengan persentase 7,308\%.

\section{DAFTAR PUSTAKA}

Achmad SA. 1986. Kimia Organik Bahan Alam. Jakarta: Departemen Pendidikan dan Kebudayaan Universitas Terbuka.

Agoes, A. 2010. Tanaman Obat Indonesia. Salemba Medika: Jakarta.

Ahmad, F., J. 2008. Manfaat Tanaman Obat. Edsa Mahkota: Jakarta.

Anderson O. M., and Markham K. R. 2006. Flavonoids: Chemistry, Biochemistry, and Application. Taylor \& Francis Group: USA.

Anonim. 2013.

Eugenin. http://en.wikipedia.org/wiki/Eugenin Diakses 20 Desember 2013.

Anonim. 2013.

Eugenitin. http://en.wikipedia.org/wiki/Eugenitin Diakses 20 Desember 2013.

Anonim. 2013.

Kaempferol. http://en.wikipedia.org/wiki/Kaempherol Diakses 20 Desember 2013. 
Anonim. 2013.

Rhamnetin.

http://en.wikipedia.org/wiki/Rhamnetin

Diakses 20 Desember 2013.

Anonymous. $2013 . \quad$ Cengkeh . http://www.iptek.net.id/ind/pd_tanobat/view. php? id=9 Diakses 20 Desember 2013.Pokja AMPL., 2011, Buku Putih Sanitasi Daerah., diakses pada 11 Februari 2016, <www://ampl.or.id/50114/overview>.

Chang C. Yang M, Wen Hand Chern J. 2002. Estimation of Total Flavonoid Content in Propolis by Two Complementary Colorimetric Methods, J. Food Drug Anal.

Cristobal, M dan Donald, R 2000. Aktifitas Antioksidan Flavonoid. Oregon State University.

Direktorat Jendral Pengawasan Obat dan Makanan. 1986. Sediaan Galenik. Departemen Kesehatan Republik Indonesia: Jakarta.

Direktorat Jendral Pengawasan Obat dan Makanan. 1989. Materia Medika Indonesia Jilid V. Departemen Kesehatan Republik Indonesia. Jakarta.

Direktorat Jendral Pengawasan Obat dan Makanan. 2000. Parameter Sediaan Umum Ekstrak Tumbuhan Obat. Departemen Kesehatan Republik Indonesia. Jakarta.

Ferdinanti, E. 2001. Uji aktivitas antibakteri obat kumur minyak cengkeh (Syzygium aromaticum (L) Merr \& Perry) asal bunga, tangkai bunga, dan daun cengkeh terhadap bakteri. (Skripsi). Jakarta: Institut Sains dan Teknologi Nasional.

Fitria. 2007. Isolasi dan Identifikasi Senyawa Flavonoid dalam daun paliasa. (Skripsi). Universitas Hasanudin: Makassar.

Harborne, J., B. 1987. Metode Fitokimia: Penuntun Cara Modern Menganalisa Tumbuhan Terbitan Kedua. Terjemahan Kosasih Padmawinata dan Iwang Soediro. ITB: Bandung.

Harborne, J., B. 1996. Metode Fitokimia edisi kedua. ITB: Bandung.

Hardjono, L. 1995. Teknologi Kimia Bagian II. Prandnya Paramita: Jakarta.

Haris, M. 2011. Penetapan Kadar Flavonoid Total dan Aktifitas Antioksidan dari Daun Dewa (Gynura pseudochina [Lour] DC) Dengan Spektrofotometer UV- Visible. (Skripsi). Padang: Universitas Andalas.

Heinrich, M., Barnes, J., Gibbons, S., Williamson, E., M. 2010. Farmakognosi dan Fitoterapi. Penerbit Buku Kedokteran: Jakarta.

Husnah, Muhibbatul. 2009. Identifikasi dan Uji Aktivitas Golongan Senyawa Antioksidan
Ekstrak Kasar Buah Pepino (Solanum muricatum Aiton) Berdasarkan Variasi Pelarut. (Skripsi). Malang: Universitas Islam Negeri Malang.

Integrated Taxonomic Information System. 2013. http://itis.gbif.net/pls/itisca/taxastep? king $=e v$ ery\&paction $=$ containin \& taxa $=$ syzygium $+a r$ omaticum \&pformat $=\&$ pif $x=$ plglt \&plang. Diakses tanggal 4 Oktober 2013.

Kar, A. 2005. Pharmaceutical Drug Analysis. New Age International Publisher: New Delhi.

Khopkar, S., M. 2008. Konsep Dasar Kimia Analitik. UI-Press: Jakarta.

Lenny, Sovia. 2006. Senyawa Flavonoid, Fenilpropanoida dan Alkaloida. Medan: Universitas Sumatera Utara.

Lumbessy, M., Abidjulu, J., Paendong, J., J., E. 2013. Uji Total Flavonoid Pada Beberapa Tanaman Obat Tradisonal Di Desa Waitina Kecamatan Mangoli Timur Kabupaten Kepulauan Sula Provinsi Maluku Utara. Jurnal Mipa UNSRAT Online 2 (1) 50-54.

Marais J., P., J., Deavours B., Dixon R., A., Ferreiraa D. 2006. The Stereochemistry of Flavonoids. In; Grotewold E (ed). The Science Of Flavonoids. Springer: Ohio.

Markham, K.,R. 1988. Cara Mengidentifikasi Flavanoid. Terjemahan Kosasih Padmawinata, Penerbit ITB: Bandung.

Miller, A., L. 1996. Antioxidant Flavonoids: Structure, Function and Clinical Usage. Alt. Med. Rev. 1(2).

Mujahid, R. 2011. Pemilihan Metode Analisis Flavonoid Secara Spektroskopi UV-Vis Serta Penerapannya Pada Seledri (Apium graviolens L.) Murbei (Morus alba L.) Patikan kebo (Euphorbia hirta L.) Dan jeruk nipis (Citrus aurantifolia) (Tesis). Fakultas Farmasi UGM: Yogyakarta.

Mulja, M dan Suharman. 1995. Analisis Instrumental. Universitas Airlangga-Press: Surabaya.

Nasution, M., R., Permana, D., \& Arif, M. 2011. Pengaruh Pemberian Rutin dan Kuersetin Terhadap Keastabilan Pigmen Antosianin dari Kelopak Bunga Rosella. Scientia Vol. 1 No. 2.

Nurdjannah, N. 2004. Diversifikasi Penggunaan Cengkeh. Perspektif Volume 3 Nomor 2.

Pourmourad, F, Hosseinimehr, S., J, Shahabimajd, N. 2006. Antioxidant Activity, Phenol And Flavonoid Contents of Some Selected Iranian Medicinal Plants. African journal of Biotechnology Vol. 5(11). 
Pramono, S. 1989. Pemisahan Flavonoid. Pasca Sarjana Fakultas Farmasi Universitas Gajah Madah: Yogyakarta.

Robinson, T. 1995. Kandungan Organik Tumbuhan Tinggi. Terjemahan Kosasih Padmawinata. ITB: Bandung.

Sudjadi. 2010. Kimia Analisis Farmasi. Pustaka Pelajar: Yogyakarta.

Sumarno. 2001. Kromatografi Teori Dasar. Bagian Kimia Farmasi Fakultas Farmasi UGM: Yogyakarta.

Suyanto, F. 2009. Efek Larvasida Ekstrak Kulit Buah Manggis (Garcinia mangostana L.) Terhadap Larva Aedes aegypti $L$. (Skripsi). Fakultas Kedokteran Universitas Sebelas Maret: Surakarta.

Tenriugu, A.D.P, Alam G, Attamim F. 2008. Standarisasi Mutu Daun Gedi (Abelmoschus manihot (L.) Medik) dan Uji Efek Antioksidan Dengan Metode DPPH (Jurnal). http://pasca.unhas.ac.id/jurnal/files/d1043b1c e802ee8dbcb6f1dbb5626d55.pdf Diakses 28 Januari 2014.

Wildah, Dj. 2001. Isolasi dan Identifikasi Flavonoid Pada Daun Kemuing (Skripsi). Jurusan Farmasi Fakultas MIPA. Universitas Hasanudin: Makassar.

Winarno, F., G. dan Sri Laksmi. 1986. Pigmen dalam Pengolahan Pangan. Dep. Tekn. Hasil Pertanian, FATAMETA - IPB, Bogor.

Wiryawan, A., dkk. 2008. Kimia Analitik. Departemen Pendidikan Nasional: Jakarta. 
1. Naskah dapat merupakan hasil penelitian eksperimental, survei, atau telaah pustaka yang erat kaitannya dengan bidang kefarmasian, kesehatan, dan lingkungan hidup.

2. Naskah berupa penelitian harus belum dan tidak pernah dipublikasikan.

3. Naskah berupa ketikan asli ditulis dalam bahasa Indonesia dengan intisari bahasa Inggris.

4. Sistematika penulisan ditulis dengan urutan sebagai berikut :
a. judul diusahakan cukup informatif dan tidak terlalu panjang dengan menggunakan huruf kapital times new roman font 14 .
b. nama (nama-nama) penulis (tanpa gelar) dan institusi/alamat tempat bekerja ditulis lengkap dan jelas.
c. intisari dan kata kunci dalam bahasa Inggris. Intisari tidak boleh lebih dari 200 kata dan kata kunci (keywords) terdiri dari 1 - 5 kata.
d. pendahuluan berisi latar belakang, tujuan penelitian, masalah yang mendasari penelitian dan tinjauan teori.
e. metode penelitian menguraikan bahan dan alat yang digunakan dan jalannya penelitian.
f. hasil dan Pembahasan
g. kesimpulan dan saran
h. ucapan terima kasih (bila ada), dan
i. daftar pustaka

5. Cara penulisan: abstrak ditulis dengan jarak 1 spasi dan naskah 2 spasi, panjang naskah maksimal 15 halaman, dengan format atas dan kiri berjarak $4 \mathrm{~cm}$, kanan dan bawah $3 \mathrm{~cm}$ dari tepi kertas ukuran kwarto/A4, dengan huruf times new roman font 12.

6. Tabel harus utuh dan jelas terbaca dengan judul tabel di bagian atas dengan nomor urut angka arab.

7. Gambar serta grafik digabungkan dalam naskah yang utuh, besarnya maksimal 1 halaman dan minimal 1/4 halaman dengan judul di bagian bawah dengan nomor urut angka arab.

8. Pengutipan pustaka dalam naskah ditulis dalam sistem nama-tahun. Bila pustaka mempunyai lebih dari dua penulis diikuti dkk., atau et al., lalu tahun.

9. Daftar pustaka disusun berdasarkan abjad.

10. Apabila diperlukan ucapan terima kasih, supaya dicantumkan di bagian akhir naskah dengan menyebut secara lengkap: nama, gelar dan penerima ucapan atau lembaga.

11. Naskah dikirim melalui alamat e-mail editorjfi@umi.ac.id.

12. Naskah yang diterima akan dikoreksi, jika ada perbaikan akan diberi catatan dan dikirimkan kepada penulis untuk dikoreksi dan dilakukan pembetulan, kemudian penulis mengirimkan kembali naskah yang telah dibetulkan melalui email editor.

13. Penulis yang naskahnya dimuat akan menerima terbitan dua eksemplar. 